\title{
Girassol: emergência e crescimento inicial de plantas sob resíduos de cana-de-açúcar
}

\author{
Sunflower - emergence and initial plant growth under sugarcane residues
}

\author{
Nilza Patrícia Ramos ${ }^{\mathrm{I}}$ Maria do Carmo de Salvo Soares Novo ${ }^{\mathrm{II}}$ Antônio Augusto Lago ${ }^{\mathrm{II}}$ \\ Maria Regina Gonçalves Ungaro ${ }^{\text {II }}$
}

\section{RESUMO}

O objetivo do trabalho foi avaliar o efeito da palha residual da colheita da cana-de-açúcar e da adição de vinhaça sobre o solo na emergência e no crescimento inicial de cultivares de girassol. Os tratamentos foram dispostos em esquema fatorial (5 $\times 2 \times 3$ ), em blocos ao acaso, com quatro repetições, combinando-se cinco quantidades de palha de cana-de-açúcar $(0,5,10,15$ e 20t ha-1) com aplicação ou não de $150 \mathrm{~m}^{3} \mathrm{ha}^{-1}$ de vinhaça residual da indústria sulcroalcooleira, utilizando-se três cultivares de girassol ("IAC-iarama", "Catissol" $e$ "Helio 358”). Foram determinadas a velocidade e a porcentagem final de emergência de plântulas, além do comprimento e da biomassa seca da parte aérea de plantas aos 30 dias após a semeadura. Verificou-se que a presença da palha de cana-de-açúcar e da vinhaça, em quantidade equivalente a $150 \mathrm{~m}^{3} \mathrm{ha}^{-1}$, em ação conjunta ou isolada, reduz a emergência de plântulas e o crescimento inicial de cultivares de girassol. Entretanto, essa redução não compromete drasticamente o desempenho das cultivares ("IAC-iarama", "Catissol” e "Helio-358”), que não diferiram entre si.

Palavras-chave: palha, vinhaça, oleaginosa, Helianthus annuus $\mathrm{L}$.

\section{ABSTRACT}

The aim of this research was to evaluate the effect of the interaction of soil cover with sugarcane mulch residue combined with vinasse application on seedling emergence and initial growth of sunflower cultivars. A greenhouse experiment was carried out in pots with soil, in randomized complete blocks, with four replications. The treatments, arranged in a $5 \times 2 \times 3$ factorial, consisted of the combination of five quantities of sugarcane mulch residue cover $\left(0,5,10,15\right.$ and $\left.20 t h^{-1}\right)$ followed by application or not of $150 \mathrm{~m}^{3} \mathrm{ha}^{-1}$ of vinasse, on soil planted to the sunflower cultivars 'IAC-iarama', 'Catissol' $e$ 'Helio 358'. The variables studied were seedling emergence speed, final emergence, as well as plant height and dry weight of above ground plant biomass. It is concluded that, under greenhouse conditions, the presence of sugarcane mulch residue in any of the quantities studied, and of vinasse in the quantity of $150 \mathrm{~m}^{3} h \mathrm{~h}^{-1}$, either isolated or in combination, reduce seedling emergence and hamper the initial growth of sunflower, but this effect is not so drastic to endanger the cultivars development ('IAC-iarama', 'Catissol' e 'Helio-358'), that do not differ between them.

Key words: mulch, vinasse, oilcrop, Helianthus annuus $\mathbf{L}$.

\section{INTRODUÇÃO}

O incentivo do governo brasileiro ao uso de fontes alternativas e limpas de energia tem contribuído para o incremento na demanda pelo etanol combustível e também pelo biodiesel, de óleos vegetais. Com isso, a expansão da cana-de-açúcar (Saccharum officinarum) para novas áreas agrícolas já é uma realidade e está atrelada ao interesse do setor em explorar as áreas de reforma dos canaviais com culturas oleaginosas. Entre as opções, destacam-se o amendoim (Arachis hypogaea L.), que já é cultivado neste sistema produtivo no Estado de São Paulo desde 1997 (BORSARI FILHO, 2006), e o girassol (Helianthus annuus L.), que, além de o menor custo de produção, tem ainda outras vantagens, tais como o incremento

'Embrapa Meio Ambiente, CP 69, 13870-000, Jaguariúna, SP, Brasil. E-mail: npramos@cnpma.embrapa.br. Autor para correspondência.

IIInstituto Agronômico (IAC), Campinas, SP, Brasil. 
na produção da cana-de-açúcar na ordem de 30\% após seu cultivo (AMBROSANO et al., 2005), o elevado teor de óleo e o ciclo mais curto.

A recomendação efetiva do cultivo do girassol em sistema de rotação com a cana-de-açúcar exige alguns cuidados, principalmente, se considerada a presença de resíduos sobre o solo. Isso porque em virtude da proibição legal das queimadas nos canaviais no Estado de São Paulo até o ano de 2031 há uma intensificação do uso da colheita de cana-crua mecanizada, que pode deixar camadas de até $10 \mathrm{~cm}$ de palha ou 20t ha-1 de resíduos na superfície do solo. Essa barreira física reduz a incidência da luz e modifica o microclima local, podendo prejudicar a emergência e o crescimento das plantas em função de efeitos negativos provocados nos processos de germinação das sementes e emergência das plântulas (TREZZI \& VIDAL, 2004).

O aproveitamento da vinhaça gerada durante a produção do etanol como fertilizante agrícola também é uma prática cada vez mais comum do setor sucroalcooleiro, utilizada com o objetivo de reduzir os custos de produção e de evitar o descarte desse resíduo para águas superficiais e lençóis freáticos (VOLL, 2005). Esse resíduo tem alto valor fertilizante por possuir elevado teor de potássio e matéria orgânica. Entretanto, seu uso deve ser feito com cautela, pois assim como são verificadas alterações com a presença da palha sobre a superfície do solo, a adição da vinhaça também tende a modificar o fluxo de emergência e o crescimento inicial de plantas pela elevação do $\mathrm{pH}$ e da matéria orgânica, aumentando a disponibilidade de alguns nutrientes, o poder de retenção dos cátions e a atividade microbiana nas áreas de semeadura e plantio (GLÓRIA, 1992).

Os processos de germinação de sementes e emergência de plântulas dependem da disponibilidade de água e oxigênio, além da temperatura do substrato, sendo que qualquer alteração no ambiente de semeadura pode prejudicar ou favorecer esses processos (CARVALHO \& NAKAGAWA, 2000). Neste contexto, o objetivo do trabalho foi avaliar o efeito da interação palha de cana-de-açúcar e aplicação de vinhaça na emergência e no crescimento inicial de cultivares de girassol.

\section{MATERIAL E MÉTODOS}

O experimento foi conduzido em casa-devegetação do Centro de Ecofisiologia e Biofísica do Instituto Agronômico (IAC), Campinas, SP, durante o período de setembro a outubro de 2005. Foram utilizados vasos plásticos de 4,0L de capacidade, preenchidos com 2,7L de terra peneirada, proveniente de um horizonte A moderado com textura argilosa, de Latossolo Roxo, apresentando $\mathrm{pH}\left(\mathrm{CaCl}_{2}\right)=5$,2, matéria orgânica $=25 \mathrm{~g} \mathrm{dm}^{-3}, \mathrm{P}$ (resina) $=1 \mathrm{mg} \mathrm{dm}^{-3}, \mathrm{~K}=0,9$, Ca $=23, \mathrm{Mg}=6, \mathrm{H}+\mathrm{Al}=28, \mathrm{SB}=29,9, \mathrm{CTC}=57,7$, expressos em mmol $\mathrm{dm}^{-3} \mathrm{eV}=52 \%$. O solo foi corrigido e adubado de acordo com as recomendações de QUAGGIO \& UNGARO (1997) e a irrigação foi realizada sempre que necessária.

Inicialmente, para a caracterização fisiológica dos lotes de girassol, foram determinadas as porcentagens de germinação de sementes e a emergência de plântulas, seguindo procedimentos descritos em BRASIL (1992), além da velocidade de emergência de plântulas, segundo MAGUIRE (1962). Posteriormente, os tratamentos foram dispostos em esquema fatorial $5 \times 2 \times 3$, em blocos ao acaso, com quatro repetições, combinando-se cinco quantidades de palha de cana-de-açúcar $(0,5,10,15$ e 20t ha-1) com aplicação ou não de $150 \mathrm{~m}^{3} \mathrm{ha}^{-1}$ de vinhaça residual da indústria sulcroalcooleira, em três cultivares de girassol, sendo "IAC-iarama” e "Catissol” de polinização aberta e "Helio 358”, híbrido.

Em cada vaso, foram colocadas, a $0,03 \mathrm{~m}$ de profundidade, dez sementes tratadas com Thiran 0,2\%, sendo logo em seguida aplicados os tratamentos com palha seguido de adição da vinhaça. A palha utilizada, proveniente da cultivar “SP 803280”, amplamente plantada no Estado de São Paulo, foi cortada em pedaços, com auxílio de tesoura, e distribuída sobre a superfície do solo, de modo a ocupar toda a superfície do vaso. As espessuras da camada disposta nos vasos foram de 0,04, 0,06, 0,09 e 0,10m, correspondentes às quantidades de 5, 10, 15 e 20t ha ${ }^{-1}$ respectivamente. A vinhaça utilizada, proveniente de lagoas de decantação da Usina Ester, Cosmópolis, SP, que apresentou em sua composição química $\mathrm{pH}=4,1, \mathrm{~N}$ total $=50,1, \mathrm{~N}$ amoniacal $=0,4, \mathrm{~N}$ nitrato $=0,2, \mathrm{~N}$ nitrito $=24,4, \mathrm{PO}_{4}$ total $=1,513,0, \mathrm{~K}=1477,0, \mathrm{Ca}=525,0, \mathrm{Mg}=1435,0$, $\mathrm{SO}_{4}=99,6$, expressos em $\mathrm{mg} \mathrm{L}^{-1}$ e $\mathrm{CE}=5,8 \mathrm{dS} \mathrm{m} \mathrm{m}^{-1}$, foi aplicada com auxílio de regador munido de placa crivada, diretamente sobre o solo, no caso do tratamento sem adição de palha, e sobre as diferentes quantidades de palha, nos demais tratamentos.

A porcentagem final de emergência de plântulas (EM) foi avaliada seguindo recomendações de BRASIL (1992), contando-se o número de plântulas normais aos 15 dias após a semeadura. Concomitante a este teste, realizou-se a contagem diária do número de plântulas identificadas como normais até a estabilização desse número, para o cálculo do índice de velocidade de emergência (IVE), baseado em MAGUIRE (1962). Para a avaliação do crescimento 
inicial, aos 30 dias após a semeadura, foram feitas as seguintes determinações de altura das plantas (AP), em centímetros e da biomassa seca da parte aérea de plantas (BSPA), expressa em gramas, que foi medida logo após a remoção e o corte das plantas, seguida de secagem em estufa, sob circulação forçada de ar a $65^{\circ} \mathrm{C}$, até a obtenção de massa constante.

Os dados foram submetidos à análise de variância empregando-se o teste $\mathrm{F}$ e transformando-se os dados em porcentagem arco seno $\sqrt{x / 100}$. Em caso de significância, a comparação das médias de cultivares e as médias de aplicação ou não de vinhaça foi feita pelo teste de Duncan, com nível de 5\% de probabilidade. Para o efeito de quantidade de palha, foi usado ajuste empregando-se funções matemáticas. Foi utilizado o sistema SANEST para computadores (ZONTA \& MACHADO, 1984).

\section{RESULTADOS E DISCUSSÃO}

A caracterização preliminar do potencial fisiológico dos lotes de sementes de girassol permite observar que todas as cultivares encontravam-se com alta porcentagem de germinação, sendo a média observada de 97\%, e excelente emergência de plântulas (média de 100\%), sem diferir estatisticamente entre si. A elevada porcentagem de emergência (EM) e o bom índice de velocidade de emergência - IVE - (média de 1,64) indicam o alto vigor dos lotes estudados, mostrando que variações de desempenho durante a condução do ensaio não seriam, potencialmente, influenciadas pelo vigor inicial das sementes.

A análise de variância revelou efeito significativo da interação entre cultivar e palha para IVE e biomassa seca da parte aérea (BSPA). Entretanto, a interação entre cultivares e vinhaça não foi significativa para nenhuma variável avaliada, enquanto que a interação entre vinhaça e palha foi significativa para EM, IVE e BSPA. Individualmente, todos os fatores interferiram no desempenho inicial do girassol.

Diferenças entre cultivares foram observadas tanto na altura média de plantas (AP) como na BSPA (Figura 1), sendo a "Helio 358” a que mais se destacou das demais cultivares, que não diferiram entre si. Os maiores valores de AP e BSPA podem estar associados ao fato desse genótipo ser híbrido e da “Catissol” e "IAC-iarama” serem variedades de polinização aberta, com menor vigor de heterose.

Com relação ao efeito isolado da palha, tanto a EM como o IVE do girassol foram afetados com incrementos neste fator (Figura 2). Houve redução linear na emergência (Figura 2A) em função do acréscimo da palha depositada sobre o solo. Também
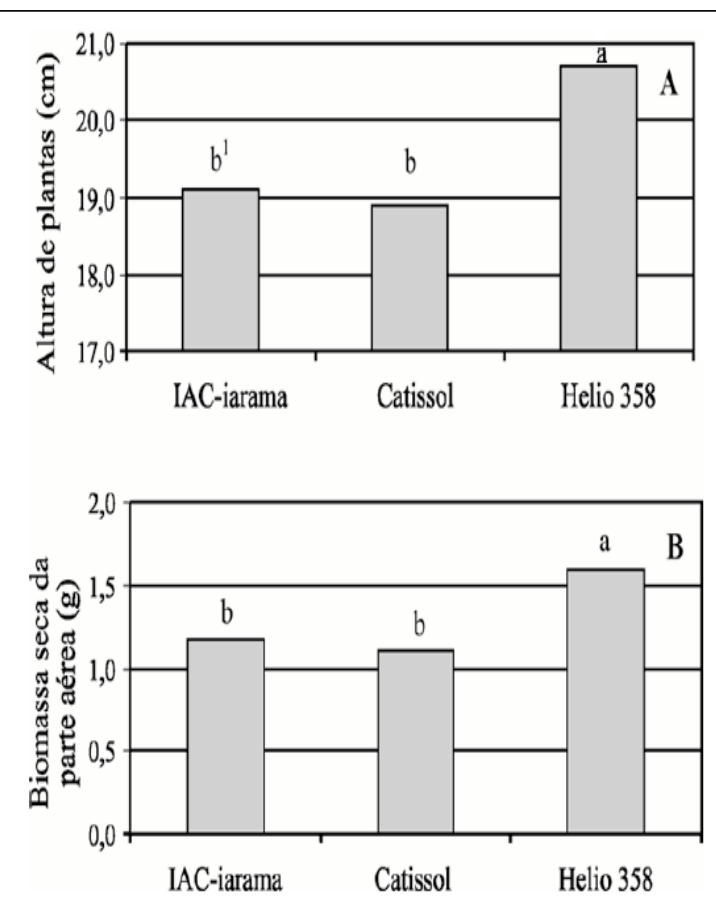

${ }^{1}$ Médias não seguidas de mesma letra, dentro de cada variável, diferem entre si a 5\% de probabilidade de erro pelo Teste de Duncan.

Figura 1 - Altura de plantas (A) e biomassa seca da parte aérea de plantas (B) de girassol em função de diferentes cultivares. Campinas-SP.

o IVE foi reduzido com o aumento da palhada (Figura 2B), sendo estimado que o menor valor seria obtido com 13,5t ha-1. Segundo TEASDALE (1996), a deposição da palha sobre o solo ocasiona mudança nas condições químicas, físicas e biológicas do ambiente edáfico e pode afetar a emergência e o crescimento das plantas, dependendo da espécie.

A presença da palha sobre a superfície do solo, normalmente, atrasa a absorção de calor, reduzindo as oscilações térmicas entre o período diurno e noturno. Isso pode retardar sensivelmente a velocidade de emergência das sementes de espécies que exigem alternâncias de temperatura para a melhor emergência de plântulas, corroborando com o que foi observado nesse experimento. Para as condições brasileiras, recomenda-se, para germinação de sementes de girassol, as temperaturas alternadas de $20-30^{\circ} \mathrm{C}$ ou constantes de $25^{\circ} \mathrm{C}$ e $30^{\circ} \mathrm{C}$ (BRASIL, 1992).

Ao serem comparados os resultados de emergência inicial das cultivares (média de 100\%) com os resultados obtidos após a adição de palha, verificouse redução acentuada de aproximadamente 28 pontos percentuais, indicando que a presença da palha 


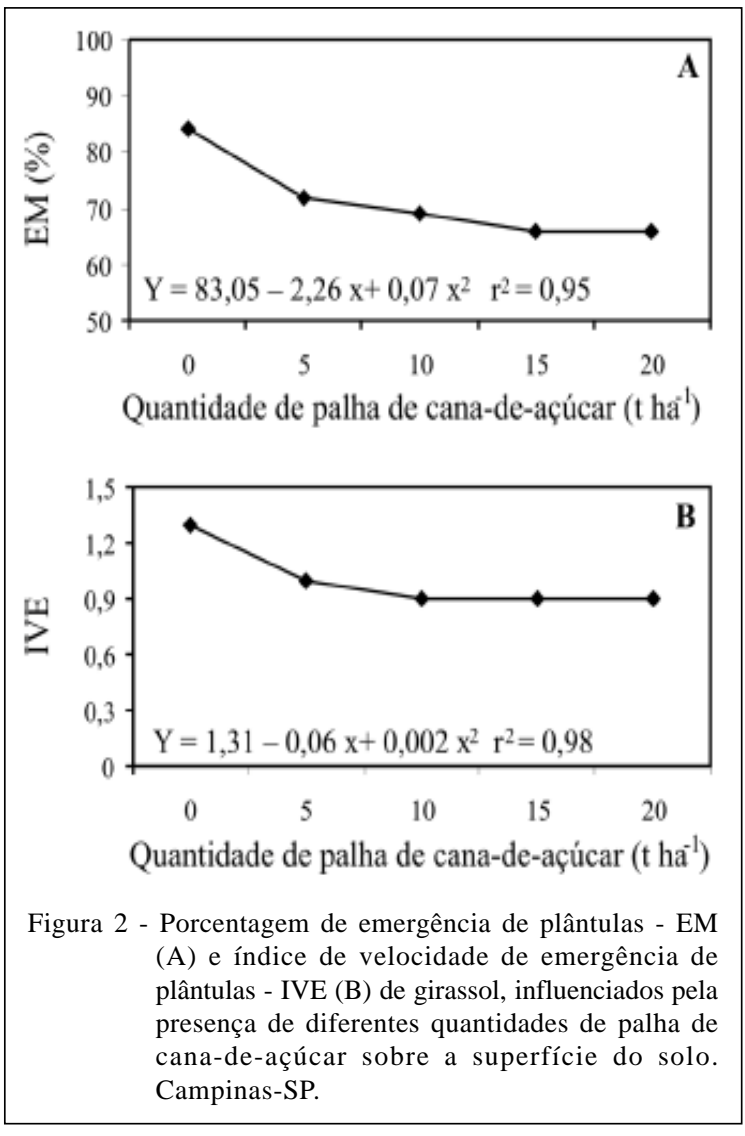

prejudicou a EM, independente da cultivar. Isso foi confirmado pela ausência de significância para o efeito cultivares tanto na EM como no IVE de girassol, sendo as médias de $72 \%$ e 1.01 , respectivamente.

Na tabela 1, são apresentados os valores médios de IVE e BSPA, referentes ao efeito de palha vs. cultivares. Houve decréscimo do IVE com o aumento da quantidade de palha adicionada ao solo, sendo o efeito mais pronunciado sobre as variedades de polinização aberta. Não houve interferência no IVE e na BSPA do híbrido Hélio 358 com o aumento da camada de palha de cana-de-açúcar sobre a superfície do solo. O IVE da "IAC-iarama" foi reduzido até a quantidade estimada de $11,7 \mathrm{t} \mathrm{ha}{ }^{-1}$, enquanto que para a "Catissol" o IVE foi linearmente reduzido com o acréscimo da palha. A BSPA da cultivar "IAC-iarama" também teve redução linear, enquanto que para “Catissol” essa variável foi reduzida até a adição de $7,5 \mathrm{tha}^{-1}$.

Analisando-se as cultivares dentro de cada quantidade de palha mantida sobre o solo (Tabela 1), verificou-se que, de modo geral, para o IVE não houve consistência nos resultados, diante da pequena variação observada em cada quantidade de palha. Por outro lado, para BSPA, a "Helio 358" foi a que mais se destacou, apresentando maiores valores, independente da quantidade da palha. Assim sendo, essa cultivar pode ser uma das mais indicadas para cultivo em áreas de reforma de canavial, após colheita mecânica de genótipos que deixam elevada quantidade de palha sobre o solo.

A presença da vinhaça também interferiu significativamente na emergência e no crescimento inicial do girassol (Figura 3). Houve prejuízos para todos os parâmetros avaliados, sendo a AP, a EM, a BSPA e o IVE reduzidos em cerca de 24, 28, 42 e $49 \%$, respectivamente. Provavelmente as reduções se devem às alterações químicas nas áreas próximas às sementes. A vinhaça promove a elevação do $\mathrm{pH}$ no solo (LEAL, 2000) e também da concentração de nutrientes como potássio, magnésio e cálcio, além de alterar o teor de matéria orgânica, o poder de retenção de cátions e a

Tabela 1 - Índices de velocidade de emergência de plântulas e de biomassa seca da parte aérea de plantas influenciados pela interação entre cultivares de girassol e quantidade de palha de palha de cana-de-açúcar sobre a superfície do solo.

\begin{tabular}{|c|c|c|c|c|c|c|c|}
\hline \multirow[b]{2}{*}{ Cultivares } & \multicolumn{5}{|c|}{ Quantidade de palha $\left(\mathrm{t} \mathrm{ha}^{-1}\right)$} & \multirow{2}{*}{\multicolumn{2}{|c|}{ Equações de ajuste e coeficiente de determinação (\%) }} \\
\hline & 0 & 5 & 10 & 15 & 20 & & \\
\hline \multicolumn{8}{|c|}{ IVE } \\
\hline "IAC-iarama” & $1.3 a b^{1}$ & 1.0a & 1.0a & $0.8 \mathrm{~b}$ & $1.0 \mathrm{a}$ & $Y=1,34-0,07 x+0,003 x^{2}$ & $r^{2}=0,87$ \\
\hline “Catissol” & $1.4 \mathrm{a}$ & 1.0a & 0.9a & 1.0a & $0,8 \mathrm{c}$ & $Y=1,30-0,03 x$ & $r^{2}=0,71$ \\
\hline “Helio 358” & $1.2 \mathrm{~b}$ & $0.9 \mathrm{a}$ & $0.9 a$ & $1.0 \mathrm{a}$ & $0.9 \mathrm{~b}$ & não significativo & \\
\hline \multicolumn{8}{|c|}{ Biomassa seca da parte aérea (g) } \\
\hline "IAC-iarama" & $1.6 \mathrm{~b}^{1}$ & $1.5 \mathrm{~b}$ & $1.6 \mathrm{~b}$ & $1.4 \mathrm{~b}$ & $1.4 \mathrm{~b}$ & $Y=1,59-0,01 x$ & $r^{2}=0,69$ \\
\hline “Catissol” & $1.5 \mathrm{~b}$ & $1.4 \mathrm{~b}$ & $1.4 \mathrm{~b}$ & $1.4 \mathrm{~b}$ & $1.7 \mathrm{~b}$ & $Y=1,51-0,03 x+0,002 x^{2}$ & $r^{2}=0,86$ \\
\hline “Helio 358” & 2.0a & 2.1a & 1.9a & $2.0 \mathrm{a}$ & 1.9a & não significativo & \\
\hline
\end{tabular}

${ }^{1}$ Médias não seguidas de mesma letra na coluna, dentro de cada variável, diferem entre si a $5 \%$ de probabilidade de erro pelo Teste de Duncan.

Ciência Rural, v.39, n.1, jan-fev, 2009. 

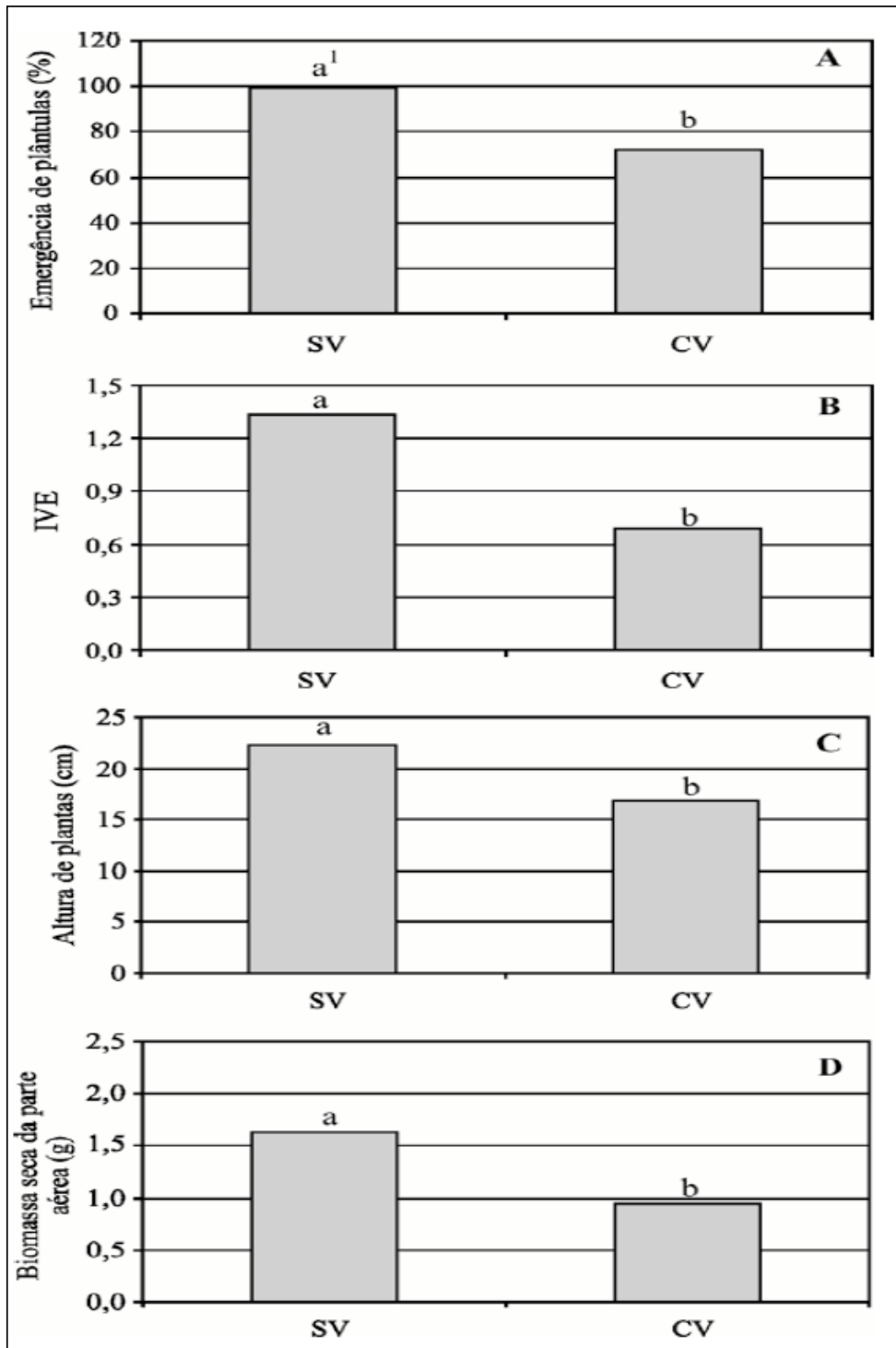

${ }^{1}$ Médias não seguidas de mesma letra, dentro de cada variável, diferem entre si a 5\% de probabilidade de erro pelo Teste de Duncan.

Figura 3 - Porcentagem de emergência de plântulas (A), índice de velocidade de emergência (B), altura (C) e biomassa seca da parte aérea de plantas (D) de girassol semeado sem aplicação de vinhaça (SV) e com aplicação de $150 \mathrm{~m}^{3} \mathrm{ha}^{-1}$ de vinhaça residual da indústria sulcroalcooleira (CV). Campinas-SP.

capacidade de retenção de água (QUINTELA et al., 2002). A maior concentração de solutos na solução do solo origina um potencial osmótico mais elevado em torno das sementes, diminuindo a velocidade de absorção de água pelas sementes e, portanto, atrasando o processo germinativo e a emergência de plântulas.

Na avaliação dos efeitos da presença da vinhaça, além de o volume aplicado, devem ser considerados fatores como adsorção de íons, maior ou menor migração das bases e facilidade de contato do soluto existente neste resíduo com a superfície do solo, sem mencionar também o tipo de solo e suas características (BRITO et al., 2005). Vale considerar que, no presente experimento, o solo utilizado foi peneirado e possuía textura argilosa, permitindo um alto contato do soluto da vinhaça com os colóides do solo. Assim, a adsorção dos nutrientes da vinhaça 
aos colóides do solo foi intensa, mas, como a dose aplicada foi elevada, houve ainda grande disponibilidade de solutos para a solução do solo, o que interferiu no IVE. BALBO JR (1984) e AZANIA et al. (2004) também observaram atrasos na emergência de plântulas em presença da vinhaça no solo durante a avaliação de sementes de plantas daninhas.

O atraso na emergência de plântulas expõe as sementes à ação dos patógenos de solo por maior período de tempo, o que aumenta a possibilidade de infecção e a colonização do eixo embrionário (MACHADO, 2000). No caso de sementes de girassol, com mais de $45 \%$ de reservas oleaginosas, esse atraso é ainda mais prejudicial, pois favorece a infecção por patógenos, além de aumentar as chances de deterioração em função da peroxidação de lipídios. VOLL (2005) observou que o efeito da vinhaça foi mais acentuado em sementes de plantas daninhas nos primeiros sete dias após a sua aplicação, sendo que este fato estava provavelmente associado à rápida deterioração das suas moléculas, principalmente das substâncias alelopáticas, em decorrência da ação dos microrganismos e dos efeitos da temperatura, da incidência luminosa e do pH. Por outro lado, MASCARENHAS et al. (1994) não verificaram diferença no estande final da cultura e em seu estabelecimento quando utilizaram vinhaça $\left(50 \mathrm{~m}^{3}\right.$ $\mathrm{ha}^{-1}$ ) como fonte de potássio na adubação de soja, fato também confirmado por AZANIA et al (2004), trabalhando com sementes de Sida rhombifolia (guanxuma) e Brachiaria decumbens (capimbraquiária) e doses de até $150 \mathrm{~m}^{3} \mathrm{ha}^{-1}$ de vinhaça. No entanto, eles verificaram redução na velocidade e na porcentagem de emergência dessas espécies em relação à testemunha, nos primeiros 20 dias de desenvolvimento, sendo observada recuperação aos 40 dias após o tratamento.

$\mathrm{Na}$ figura 4, são apresentados os resultados de EM, IVE e BSPA em função do efeito combinado entre quantidades de palha e aplicação ou não de vinhaça. Foi verificada alta significância para essa interação, sendo os tratamentos sem a presença da vinhaça estatisticamente superiores aos tratados com este resíduo em todas as variáveis citadas. O efeito combinado da palha com $150 \mathrm{~m}^{3}$ ha $^{-1}$ de vinhaça foi reduzindo a EM do girassol (Figura 4A) até a camada de 15t ha-1 de palha, quando esse parâmetro foi mais afetado, com queda de 38 pontos percentuais, tendo se elevado sensivelmente na dose de 20t ha-1. Já com relação ao IVE (Figura 4B), na ausência da vinhaça, não foi observada diferença significativa entre os tratamentos com diferentes quantidades de palha, sendo a média obtida de 1,34 , enquanto que na presença da vinhaça essa variável foi sendo reduzida até a adição estimada de 6,95t ha-1 . Para BSPA (Figura 4C), não houve efeito significativo do aumento da camada de palha na ausência da vinhaça, enquanto que em sua presença houve redução linear desta variável.

Cabe destacar que se sugere a experimentação em campo para a continuidade desta linha de estudos a fim de verificar, principalmente, os efeitos da adição da vinhaça sobre o desenvolvimento geral e a produção da cultura do girassol, uma vez que
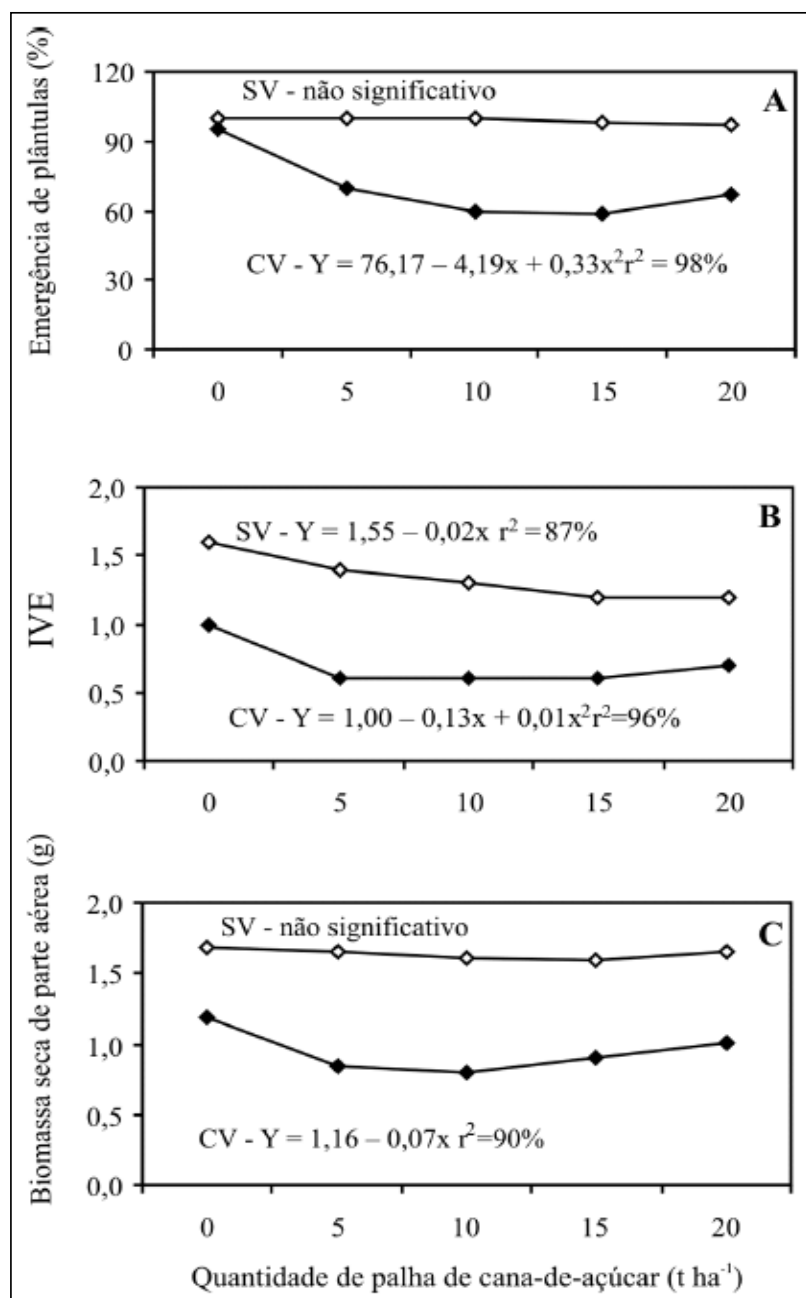

Figura 4 - Porcentagem de emergência de plântulas (A), índice de velocidade de emergência de plântulas (B) e biomassa seca de parte aérea de plantas (C) de girassol, influenciados pela presença de diferentes quantidades de palha de cana-de-açúcar associadas com a ausência na aplicação de vinhaça (SV) e com a aplicação $150 \mathrm{~m}^{3}$ ha $^{-1}$ de vinhaça (CV) residual da indústria sulcroalcooleira. Campinas-SP. 
os efeitos observados em experimentos de vasos podem ser mais restritivos em função da menor lixiviação de compostos para o perfil do solo.

\section{CONCLUSÕES}

A presença da palha de cana-de-açúcar e da vinhaça, em quantidade equivalente a $150 \mathrm{~m}^{3} \mathrm{ha}^{-1}$, em ação conjunta ou isolada, reduz a emergência de plântulas e o crescimento inicial de cultivares de girassol. Entretanto, essa redução não compromete drasticamente o desempenho das cultivares ("IACiarama”, “Catissol” e "Helio-358”), que não diferiram entre si.

\section{REFERÊNCIAS}

AMBROSANO, E.J. et al. Vantagens da utilização da rotação com girassol e outras leguminosas em áreas de reforma de canavial em Piracicaba, São Paulo. Londrina: Embrapa Soja, 2005. 206p. (Documentos Embrapa Soja n.261).

AZANIA, A.A.P.M. et al. Emergência e desenvolvimento de guanxuma (Sida rhombifolia), capim-braquiária (Brachiaria decumbens) e cana-de-açúcar (Saccharum spp.) influenciados por subprodutos da destilação do álcool. Planta Daninha, v. 22, p.331-336, 2004.

BALBO JR., L. Estudos preliminares dos efeitos da vinhaça sobre a emergência e desenvolvimento inicial de plantas daninhas. I - Fedegoso (Cassia tora L.). 1984. 41f. Monografia (Trabalho de Graduação em Agronomia) Universidade Estadual Paulista, Jaboticabal.

BORSARI FILHO, S. Potencial da cultura do amendoim como fonte de matéria-prima para o Programa Nacional de Produção e Uso de Biodiesel. In: CÂMARA, G.M.S.; HEIFFIG, L.S. Agronegócios de plantas oleaginosas - matérias-primas para biodiesel. Piracicaba: ESALQ, 2006. Cap.4, p.43-55.

BRASIL. Ministério da Agricultura e Reforma Agrária. Regras para análise de sementes. Brasília: AGIPLAN, 1992. 365p.

BRITO, F.L. et al. Teores de potássio e sódio no lixiviado e em solos após a aplicação de vinhaça. Revista Brasileira de Engenharia Agrícola e Ambiental, v.9, suplemento, p.5256, 2005.
CARVALHO, N.M.; NAKAGAWA, J. Sementes: ciência, tecnologia e produção. 4.ed. Jaboticabal: FUNEP, 2000. 588p.

GLÓRIA, N. A. Uso agronômico de resíduos. In: REUNIÃO BRASILEIRA DE FERTILIDADE DO SOLO E NUTRIÇÃO DE PLANTAS, 20., 1992, Piracicaba, SP. Anais... Piracicaba: ESALQ/USP, 1992. p.1-17.

LEAL, R. Soil management in the developing countries. Soil Science, v.165, p.57-72, 2000

MACHADO, J.C. Patologia de sementes: significado e atribuições. In: CARVALHO, N.M.; NAKAGAWA, J. Sementes: ciência, tecnologia e produção. 4.ed. Jaboticabal: FUNEP, 2000. 588p.

MAGUIRE, J.D. Speed of germination aid in selection and evaluation for seedling and vigor. Crop Science, Madison, v.2, n.2, p.176-177, 1962.

MASCARENHAS, H.A.A. et al. Efeito de adubos potássicos na produção de soja. Scientia Agrícola, Piracicaba, v.51, n.1, p.82-89, 1994.

QUAGGIO. J.A.; UNGARO, M.R.G. Girassol. In: RAIJ, B. et al. Recomendações de adubação e calagem para o estado de São Paulo. 2.ed. Campinas: Instituto Agronômico ; Fundação IAC, 1997. p.198.

QUINTELA, A.C.R. et al. Controle de plantas daninhas em cana crua (cultivar RB835089) no sistema integrado palhiço, herbicida e vinhaça. STAB, v.20, p.38-42, 2002.

TEASDALE, J.R. Contribution of cover crops to weed management in sustainable agricultural systems. Journal of Production Agriculture, v.9, p.475-479, 1996.

TREZZI, M.M.; VIDAL, R.A. Potencial de utilização de cobertura vegetal de sorgo e milheto na supressão de plantas daninhas em condição de campo: II - Efeitos da cobertura morta. Planta Daninha, v.22, p. 1-10, 2004

VOLL, C.E. Aplicação de vinhaça e do extrato de palhiço de cana-de-açúcar no controle de plantas daninhas. 2005. 45f. Dissertação (Mestrado em Fitotecnia) - Curso de Pósgraduação em Agronomia, ESALQ Universidade de São Paulo.

ZONTA, E.P.; MACHADO, A.A. Sistema de análise estatística para microcomputadores - SANEST. Pelotas: UFPEL, 1984. 109p. 